\title{
The role of Mesothelin signaling in Portal Fibroblasts in the pathogenesis of cholestatic liver fibrosis
}

\author{
Hiroaki Fuji ${ }^{1,2+}$, Grant Miller ${ }^{1,2 \dagger}$, Takahiro Nishio ${ }^{3}$, Yukinori Koyama ${ }^{3}$, Kevin Lam ${ }^{1,2}$, \\ Vivian Zhang ${ }^{1,2}$, Rohit Loomba ${ }^{1}$, David Brenner ${ }^{1}$ and Tatiana Kisseleva ${ }^{2 *}$ \\ ${ }^{1}$ Department of Medicine, University of California San Diego, La Jolla, CA, United States, ${ }^{2}$ Department of Surgery, University of \\ California San Diego, La Jolla, CA, United States, ${ }^{3}$ Department of Surgery, Graduate School of Medicine, Kyoto University, Kyoto, \\ Japan
}

\section{OPEN ACCESS}

Edited by: Enis Kostallari,

Mayo Clinic, United States

Reviewed by:

Ezhilarasan Devaraj,

Saveetha University, India Maria Eugenia Guicciardi, Mayo Clinic, United States

*Correspondence:

Tatiana Kisseleva

tkisseleva@health.ucsd.edu

${ }^{t}$ These authors have contributed equally to this work and share first authorship

Specialty section:

This article was submitted to Molecular Diagnostics and Therapeutics,

a section of the journal Frontiers in Molecular Biosciences

Received: 05 October 2021 Accepted: 15 November 2021 Published: 13 December 2021

Citation:

Fuji $H$, Miller $G$, Nishio $T$, Koyama $Y$, Lam K, Zhang V, Loomba R, Brenner D and Kisseleva $T$ (2021) The role of

Mesothelin signaling in Portal Fibroblasts in the pathogenesis of cholestatic liver fibrosis.

Front. Mol. Biosci. 8:790032. doi: 10.3389/fmolb.2021.790032
Liver fibrosis develops in response to chronic toxic or cholestatic injury, and is characterized by apoptosis of damaged hepatocytes, development of inflammatory responses, and activation of Collagen Type I producing myofibroblasts that make liver fibrotic. Two major cell types, Hepatic Stellate Cells (HSCs) and Portal Fibroblasts (PFs) are the major source of hepatic myofibroblasts. Hepatotoxic liver injury activates Hepatic Stellate Cells (aHSCs) to become myofibroblasts, while cholestatic liver injury activates both aHSCs and Portal Fibroblasts (aPFs). aPFs comprise the major population of myofibroblasts at the onset of cholestatic injury, while aHSCs are increasingly activated with fibrosis progression. Here we summarize our current understanding of the role of aPFs in the pathogenesis of cholestatic fibrosis, their unique features, and outline the potential mechanism of targeting aPFs in fibrotic liver.

Keywords: cholestatic liver fibrosis, activated portal fibroblasts, mesothelin (MSLN), mucin 16 (MUC16), thymocyte differentiation antigen 1 (Thy-1)

\section{INTRODUCTION}

Hepatic fibrosis is the outcome of chronic liver diseases, including cholestatic liver disease (primary sclerosing cholangitis (PSC), primary biliary cirrhosis (PBC), and secondary biliary cirrhosis (SBC)) (Lazaridis and LaRusso, 2016) and toxic liver injury (hepatitis B virus (HBV), hepatitis C virus (HCV), alcoholic liver disease and non-alcoholic steatohepatitis (NASH)) (Friedman, 2008; Dranoff and Wells, 2010). It is characterized by extensive deposition of extracellular matrix (ECM). Activated hepatic myofibroblasts, which are absent in the healthy liver, are the major source Collagen Type I which form the fibrous scar (Friedman, 2008). Hepatic stellate cells (HSCs) and portal fibroblasts $(\mathrm{PFs})$ are believed to serve as the major source of the fibrous scar in the injured liver (Bataller and Brenner, 2005).

Cholestatic fibrosis is caused by chronic cholestatic injury (Lazaridis and LaRusso, 2016), hepatocyte apoptosis, ductular proliferation, inflammation, and activation of myofibroblasts. Both activated PFs (aPFs) and activated HSCs (aHSCs) (Dranoff and Wells, 2010) can produce myofibroblasts that drive cholestatic fibrosis. Despite extensive studies, the origin and contribution of hepatic myofibroblasts to cholestatic fibrosis remains controversial. Several studies in humans and

Abbreviations: Msln, mouse mesothelin (human counterpart MSLN); Muc16, mouse mucin 16 (human counterpart CA125); Thy1, mouse thymocyte differentiation antigen 1 (human counterpart THY1). 
experimental models of cholestatic fibrosis implicated aPFs in the pathogenesis of cholestatic fibrosis, suggesting that aPFs might serve as the primary targets for anti-fibrotic therapy (Dranoff and Wells, 2010; Wells, 2014). In support, aPFs contribute to the fibroproliferative responses in patients with primary and secondary biliary cirrhosis (PSC and SBC), but not in patients with toxic liver fibrosis such as HBV/HCV (Koyama et al., 2017).

Under the physiological conditions, PFs comprise a small population of cells that surround the portal vein to maintain integrity of the portal tract (Dranoff and Wells, 2010). Cholestatic (but not toxic) injury (Desmoulière et al., 1997) causes their proliferation and differentiation into Collagen Type I-producing myofibroblasts( (Dranoff and Wells, 2010), (Desmoulière et al., 1997), (Yata et al., 2003)), suggesting that aPFs are the "first responders" to the cholestasis-induced fibrogenic liver injury. Using the reporter Col-GFP mice (in which Collagen-1a(I) promoter drives expression of the GFP reporter gene in real time), aPFs were shown to comprise $70 \%$ of myofibroblasts at the onset of cholestatic fibrosis caused by the obstruction of the common bile duct (BDL), that mimics mechanical bile duct occlusion by liver stones or tumor mass. Similar results were obtained using another model of cholestatic injury, $\mathrm{Mdr}^{-/-}$mice (Smit et al., 1993) (deficient for canalicular phospholipid flippase, Mdr2/Abcb4), which develop disruption of bile duct tight junctions and basal membranes, causing bile leakage, and periportal cholestatic fibrosis (Smit et al., 1993) that resembles PSC (Fickert et al., 2002; Fickert et al., 2004; Popov et al., 2005; Fickert et al., 2009; Baghdasaryan et al., 2010; Mair et al., 2010), and mimics MDR2 deficiency in patients (Jacquemin, 2001; Fickert et al., 2004; Popov et al., 2005). Moreover, cholestasisactivated aHSCs share more resemblance with aPFs than with $\mathrm{CCl}_{4}$-activated aHSCs, suggesting that fibrogenic responses caused by cholestatic fibrosis differ significantly from those induced by toxic injury, and therefore the mechanism of the cholestatic fibrosis progression should be studied in further detail (Iwaisako et al., 2014).

The contribution of aPFs to liver fibrosis of different etiologies remains not well understood, mainly because of difficulties with the isolation of PFs and myofibroblasts. The most widely used method of aPF isolation is based on enzymatic digestion followed by size selection (Wen et al., 2012), as well as cell outgrowth from dissected bile and enzymatically digested liver segments(Uchio et al., 2002), (Kruglov et al., 2002). aPFs are identified by expression of Elastin, Colla1, and other fibrogenic genes. Expression of specific markers such as Thy-1 (Knittel et al., 1999; Dudas et al., 2007; Yovchev et al., 2009; Katsumata et al., 2017), Fibulin 2 (Knittel et al., 1999), IL-6, Elastin (Goodpaster et al., 2008), the ecto-AT-Pase nucleoside triphosphate diphosphohydrolase-2 (NTPD2) (Dranoff et al., 2002), and coffilin 1 (Bosselut et al., 2010) was originally identified in aPFs, demonstrating that these cells are different from desmin, cytoglobin, GFAP, $\mathrm{p} 75^{\mathrm{NGFr}}$, and Vitamin A expressing HSCs (Bataller and Brenner, 2005; Dranoff and Wells, 2010; Fausther and Dranoff, 2011). The development of flow cytometry-based techniques made it possible to sort purify the population of hepatic Col-GFP ${ }^{+}$Thy- $1^{+} V_{\text {itamin }}^{-} \mathrm{CD}^{-} 5^{-}$ aPFs, which can be distinguished from Col-GFP ${ }^{+}$Thy-
$1^{-}$Vitamin $\mathrm{A}^{+}$aHSCs, and identified new markers of aPFs such as Mesothelin (Msln), Muc16, CD34, Gpc3, Asporin, Bnc1 (Iwaisako et al., 2014; Nishio et al., 2021). Moreover, Msln was shown to critically regulate fibrogenic activation and proliferation of aPFs in response to cholestatic injury. This review will summarize the potential role of Msln-Thy-1 and Muc16 signaling in the activation of aPFs in experimental models of cholestatic fibrosis, and discuss the emerging strategies to target aPFs to treat cholestatic liver fibrosis.

\section{CHOLESTATIC LIVER FIBROSIS}

The etiology of cholestatic injury differs considerably from toxic liver injury. Cholestatic injury results from genetic defects or mechanical injury of the bile ducts, causing impaired hepatobiliary production and excretion of bile, accumulation of bile and liver tissue damage, apoptosis and proliferation of mature cholangiocytes and hepatocytes, inflammation, and biliary fibrosis (Fickert et al., 2009; Vavassori et al., 2009; Wagner et al., 2010). Several experimental models are routinely used to dissect the mechanism of cholestatic fibrosis, such as $\mathrm{Mdr}^{-/-}$mice (Smit et al., 1993) and BDL. Despite different etiologies, these models exhibit common pathophysiological features. Reversal of the etiological cause of cholestasis may result in regression of liver fibrosis.

\section{ACTIVATED PORTAL FIBROBLASTS PLAY A KEY ROLE IN CHOLESTATIC LIVER FIBROSIS}

Activation of fibrogenic Collagen Type I producing myofibroblasts is the key event leading to the progression of cholestatic fibrosis. Myofibroblasts are characterized by a spindle or stellate shape and expression of abundant intracellular proteins (vimentin, $\alpha$-smooth muscle actin ( $\alpha$-SMA), non-muscle myosin) (Eyden, 2008), rough endoplasmic reticulum (rER) and a Golgi apparatus producing collagen (Gabbiani et al., 1971; Majno et al., 1971; Schürch et al., 1998; Eyden, 2008).

\section{The Origin of Myofibroblasts in Cholestatic Liver Fibrosis}

The cell that secretes the fibrillary collagens leading to cholestatic fibrosis has a long and controversial history (Dranoff and Wells, 2010; Mederacke et al., 2013). Due to lineage tracing studies by our lab (Iwaisako et al., 2014; Koyama et al., 2017) and others (Asahina et al., 2009; Asahina et al., 2011), there is a clear consensus that endogenous mesenchymal cells activate to become myofibroblasts that secrete the fibrous scar proteins. Fate mapping studies have also demonstrated that epithelial mesenchymal transition (EMT) (Scholten et al., 2010; Taura et al., 2010; Chu et al., 2011), or recruited fibrocytes (Kisseleva et al., 2006; Scholten et al., 2011; Iwaisako et al., 2014) are not major contributors to the myofibroblast population. In turn, two hepatic mesenchymal cells become myofibroblasts depending on 


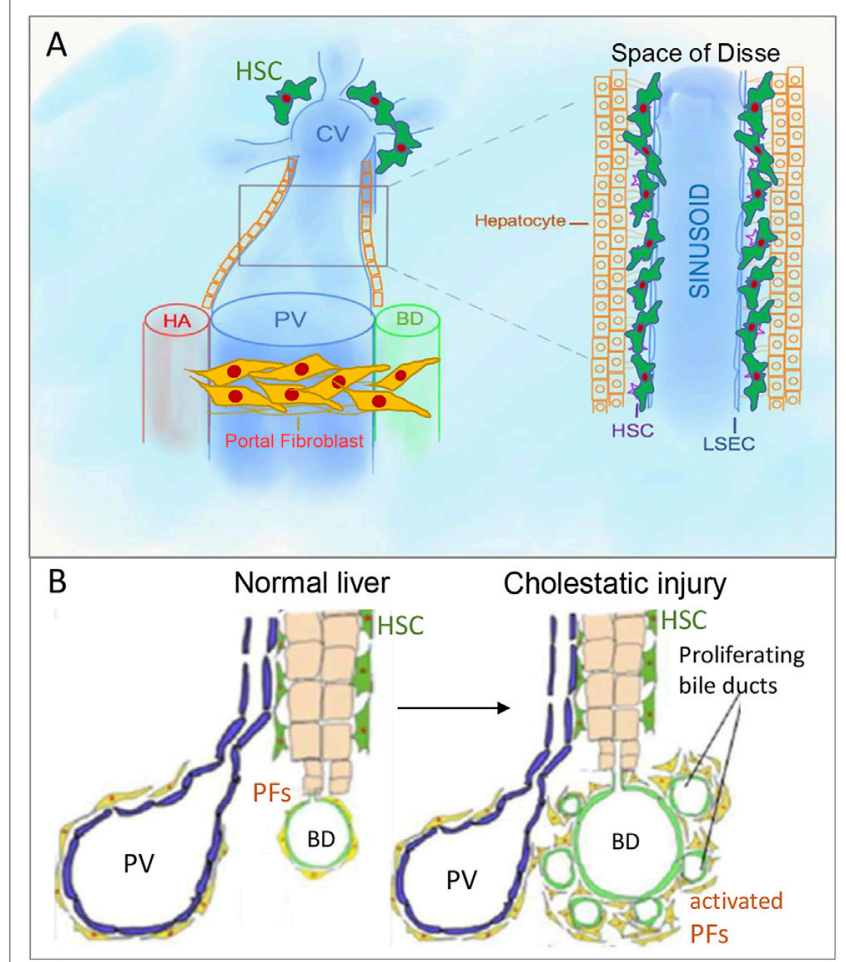

FIGURE 1 | Portal fibroblasts/myofibroblasts (aPFs/MFs) and hepatic stellate cells (HSCs). (A). PFs are located around portal triads, while HSCs are located in the space of Disse, which is between sinusoidal endothelial cells and hepatocytes cluster. (B). Bile ducts proliferate in response to bile duct ligation, known as "ductular reaction." PV, portal vein, CV, central vein, $\mathrm{HA}$, hepatic artery, BD, bile duct.

the fibrotic stimulus (Iwaisako et al., 2014). Hepatotoxic liver injury activates HSCs to become myofibroblasts, while cholestatic liver injury activates both HSCs and aPFs (Dranoff et al., 2002; Kruglov et al., 2002; Wen et al., 2012). aPFs comprise $70 \%$ of myofibroblasts at the onset of bile duct ligation (BDL)-induced injury, while aHSCs are increasingly activated with fibrosis progression (Iwaisako et al., 2014; Karin et al., 2016) (Figures 1A,B).

\section{Hepatic Stellate Cells}

Under physiological conditions, quiescent HSCs express desmin, neural markers (glial fibrillar acidic protein (GFAP), synaptophysin (Bataller and Brenner, 2005), NGF receptor p75 (Sachs et al., 2007; Kendall et al., 2009)), and Vitamin A droplets( (Iredale, 2007; Geerts, 2001; Senoo et al., 2007)) and reside in the space of Disse (Figure 1A), but in response to injury differentiate into aHSCs/myofibroblasts expressing vimentin, and collagens (Kisseleva and Brenner, 2006; Fallowfield et al., 2007).

\section{Portal Fibroblasts}

In normal liver, portal fibroblasts (PFs) comprise a small population of "periductular mesenchymal cells" that surround the portal vein and maintain integrity of the portal tract
(Figure 1B) (Desmoulière, 2007; Dranoff and Wells, 2010; Wells, 2014). In response to cholestatic injury (but not toxic carbon tetrachloride $\left(\mathrm{CCl}_{4}\right)$-induced injury) (Desmoulière et al., 1997), activated portal fibroblasts (aPFs) proliferate, upregulate Col1a1, TIMP1, Spp1, TGF $\beta$ RI, TGF $\beta 2$, and secrete extracellular matrix (ECM) (Desmoulière et al., 1997; Yata et al., 2003; Dranoff and Wells, 2010). aPFs are identified by expression of Thy-1( (Knittel et al., 1999; Dudas et al., 2007; Yovchev et al., 2009)), Fibulin 2 (Knittel et al., 1999), Elastin (Goodpaster et al., 2008), NTPD2 (Dranoff et al., 2002), coffilin 1 (Bosselut et al., 2010), Msln, Muc16, Apsorin, Bnc1, Upk1ß, Calca, Gpc3 ((Koyama et al., 2017), (Iwaisako et al., 2014)). We have recently demonstrated that Msln, Muc16 (Koyama et al., 2017), and Thy-1 (Katsumata et al., 2017) play a critical role in regulation of aPF biology.

\section{UNIQUE FEATURES OF ACTIVATED PORTAL FIBROBLASTS}

Based on gene expression profiling, BDL-activated aPFs expressed genes that distinguish them from $\mathrm{CCl}_{4}$-activated aHSCs, and were identified as "signature genes" for aPFs. In concordance with previous studies (Kawada et al., 2001; Bosselut et al., 2010), aPF signature genes included Thy-1, Elastin, Gremlin 1, Fibulin 2, and NTPD2 (Dranoff and Wells, 2010; Forbes and Parola, 2011), but also the newly identified genes, Msln, and Muc 16, Calca, Upk1 $\beta$, Bnc1 and others. Human $\mathrm{MSLN}^{+} \mathrm{THY}^{+}{ }^{+} \mathrm{aSMA}^{+}$aPFs also express aPF-specific markers (UPK1b, CD200, EMILIN2, BNC1, ASPN, GPC3, and GREM1) similar to that observed in mouse aPFs, suggesting that upregulation of these specific genes in activated PFs is preserved among species. Some of these genes Msln, Calca, Upk1 $\beta$, Bnc1 were reported as signature genes of murine hepatic mesothelial (Onitsuka et al., 2010) and epicardial cells (Bochmann et al., 2010), supporting the theory that PFs originate from mesothelial cells (Asahina et al., 2009; Asahina, 2012). Expression of Msln and Muc16 is detected in Thy- $1^{+}$aPFs but not in qHSCs, aHSCs, endothelial cells (EC), Kupffer cells (KC), or cholangiocytes. The fact that expression of Msln was detected only in isolated aPFs but not in other liver fractions suggests (Iwaisako et al., 2014) that Msln expression might be important for aPF biology.

\section{HISTORICAL CHARACTERIZATION OF MSLN, CA125 AND THY-1}

\section{Mesothelin}

Msln (Chang and Pastan, 1996) is Glycosylphosphatidyl inositol (GPI)-linked membrane-anchored protein $(71 \mathrm{kDa}, \mathrm{Msln}$ precursor). Originally, MSLN was identified as a tumor marker. Human MSLN is strongly upregulated in several human malignancies, including mesotheliomas and ovarian cancer, and is a target for anti-cancer therapy. Anti-MSLN Abs have been generated and are being tested in clinical trials in patients with ovarian cancer. 


\section{Mucin 16}

Muc16 is the murine analogue of human CA125 (McMullen et al., 2005). Studies of patients with ovarian cancer have identified the cancer antigen CA125 as a Msln ligand (Pastan and Hassan, 2014), which is widely used as a diagnostic marker (with the exception of liver and lung cirrhosis which are considered as "false positives" (Scholler and Urban, 2007). CA125 is a member of the membrane-tethered family of mucins, which contains a transmembrane domain with a short cytoplasmic domain, and highly glycosylated at N-terminus (Pastan and Hassan, 2014) and is a MSLN ligand (Gubbels et al., 2006; Kaneko et al., 2009).

\section{MsIn-Muc16 Signaling in Cancer Cells}

Since its discovery in 1992 as a cancer antigen, the mechanism of human MSLN signaling remains unresolved. Until recently, CA125 (mouse Muc16) remained the only known ligand of MSLN that activates Src/Akt signaling in cancer cells. In cancer cells MSLN-Muc16 signaling increases cancer cell proliferation and metastasis. Msln-mediated secretion of MMP-7 in MUC16-expressing cancer cells occurs via a p38 MAPK-dependent pathway. Depletion of MMP-7 or inhibition of p38 activity abolishes MSLN-mediated cancer cell motility and invasion. Knockdown of Msln suppresses tumor invasiveness in xenograft models in mice (He et al., 2017). Although, $\mathrm{Msln}^{-1-}$ and $\mathrm{Muc16}^{-1-}$ mice have a normal phenotype until injury or stress (Bera and Pastan, 2000; McMullen et al., 2005), when subjected to experimental model of liver cancer, Msln-knockout mice developed a defect in activation of cancer associated myofibroblasts (Zhang et al., 2011).

\section{MsIn as a Mesothelial Marker}

Expression of Msln is not restricted to cancer cells or cancerassociated myofibroblasts but is also induced in aPFs. Msln also serves as a mesothelial cell marker (Pastan and Hassan, 2014). Msln is highly expressed during embryonic development (Majno et al., 1971; Iwaisako et al., 2014) but minimally expressed in adulthood (Pastan and Hassan, 2014). In adult mice and humans, Msln-expressing stem-like cells reside in the mesothelial layer lining of parenchymal organs and serosal cavities (Bera and Pastan, 2000) in a dormant state, and do not proliferate until injury or stress, and have a capability to give rise to the mesenchymal and mesothelial cells, as well as fibroblasts.

\section{Thy-1 (CD90, Cluster of Differentiation 90)}

Thy-1 is a $25-37 \mathrm{kDa}$ heavily $\mathrm{N}$-glycosylated (GPI)-linked cell surface protein (Nosten-Bertrand et al., 1996), with a single V-like immunoglobulin domain, originally discovered as a thymocyte antigen.Thy-1 is a GPI-anchored protein (like Msln) (NostenBertrand et al., 1996) expressed in fibroblasts, T cells and neurons, and considered to be a specific marker for these cell types. Thy- 1 was implicated in inhibition of TGF $\beta 1$ responses in tissue fibroblasts. Studies of lung fibroblasts have demonstrated that deletion of Thy-1 in mice exacerbated bleomycin-induced lung fibrosis (Ramírez et al., 2011). Thy-1 was shown to signal via the Src-family kinase (SFK) and focal adhesion kinase (FAK) pathways (Bradley et al., 2009) to prevent TGF $\beta 1$-induced fibroblast activation (Koyama et al., 2017) and inhibition of extracellular activation of tissue-associated latent TGF- $\beta 1$ via interaction with $\alpha v-\beta 5$ integrins at the cell surface (Zhou et al., 2010), suggesting that Thy-1 can function as a mechanosensor (Fiore et al., 2015). Thy-1 expression in murine lung fibroblasts is decreased with fibrosis progression (McIntosh et al., 1994; Hagood et al., 1999; Hagood et al., 2005; Sanders et al., 2007; Zhou et al., 2010; Sueblinvong et al., 2012). Thy-1 also modulates lipid raft-associated signaling promoting fibroblast adhesion and limiting migration (Bradley et al., 2009).

\section{Thy-1 in Fibroblasts was Linked to Fibrosis}

Thy-1 is silenced in lesional fibroblasts in IPF (Idiopathic Pulmonary Fibrosis), and its expression in murine lung fibroblasts is decreased with progression of experimental bleomycin induced lung fibrosis (Hagood et al., 2005; Sueblinvong et al., 2012). Thy-1 acts as a fibrosis suppressor which prevents differentiation of lung fibroblasts into myofibroblasts (including Collagen Type I expression, cytokine and growth factor expression, migration, and cell survival). Upon activation, lung myofibroblasts upregulate TGF $\beta 1$-responsive genes (Activin and PAI-1) but downregulate expression of Thy-1 (McIntosh et al., 1994; Hagood et al., 1999; Hagood et al., 2005; Sanders et al., 2007; Zhou et al., 2010). Deletion of Thy-1 exacerbates development of cholestatic fibrosis in mice (Koyama et al., 2017; Nishio et al., 2021).

\section{MSLN SIGNALING PLAYS A CRITICAL ROLE IN ACTIVATION AND PROLIFERATION OF ACTIVATED PORTAL FIBROBLASTS}

The molecular mechanisms underlying Msln signaling in experimental models of cholestatic fibrosis have been evaluated, and demonstrated that in addition to Muc16, Msln can also bind to Thy 1 in aPFs and form a signaling Msln-Muc16Thy- 1 complex that regulates fibrogenic activation and proliferation of aPFs.

\section{$\mathrm{MsIn}^{-/-}$and Muc16 ${ }^{-/-}$Mice are Protected From Cholestatic Liver Fibrosis}

Although, Msln ${ }^{-1-}$ Muc16 $6^{-1-}$, and Thy-1 ${ }^{-1-}$ mice exhibit no obvious abnormalities under physiological conditions (Bera and Pastan, 2000; McMullen et al., 2005), these molecules play a critical role in the pathogenesis of cholestatic fibrosis. Thus, cholestatic fibrosis (caused by BDL or Mdr2 deficiency) was strongly attenuated by $\approx 50 \%$ in Msln knockout mice $\left(\mathrm{Msln}^{-1-}\right.$ mice). In vitro analysis revealed that Msln regulates TGF $\beta 1$ inducible activation of the wild type aPFs, and facilitates their FGF-FGFRI-Act-mediated aPF proliferation (via inhibition of FGFRI turnover and re-expression). Similarly, deletion of Muc16 (the binding partner of Msln and potentially the only transmembrane signaling molecule in this complex) also attenuates development of cholestatic fibrosis, outlining the 


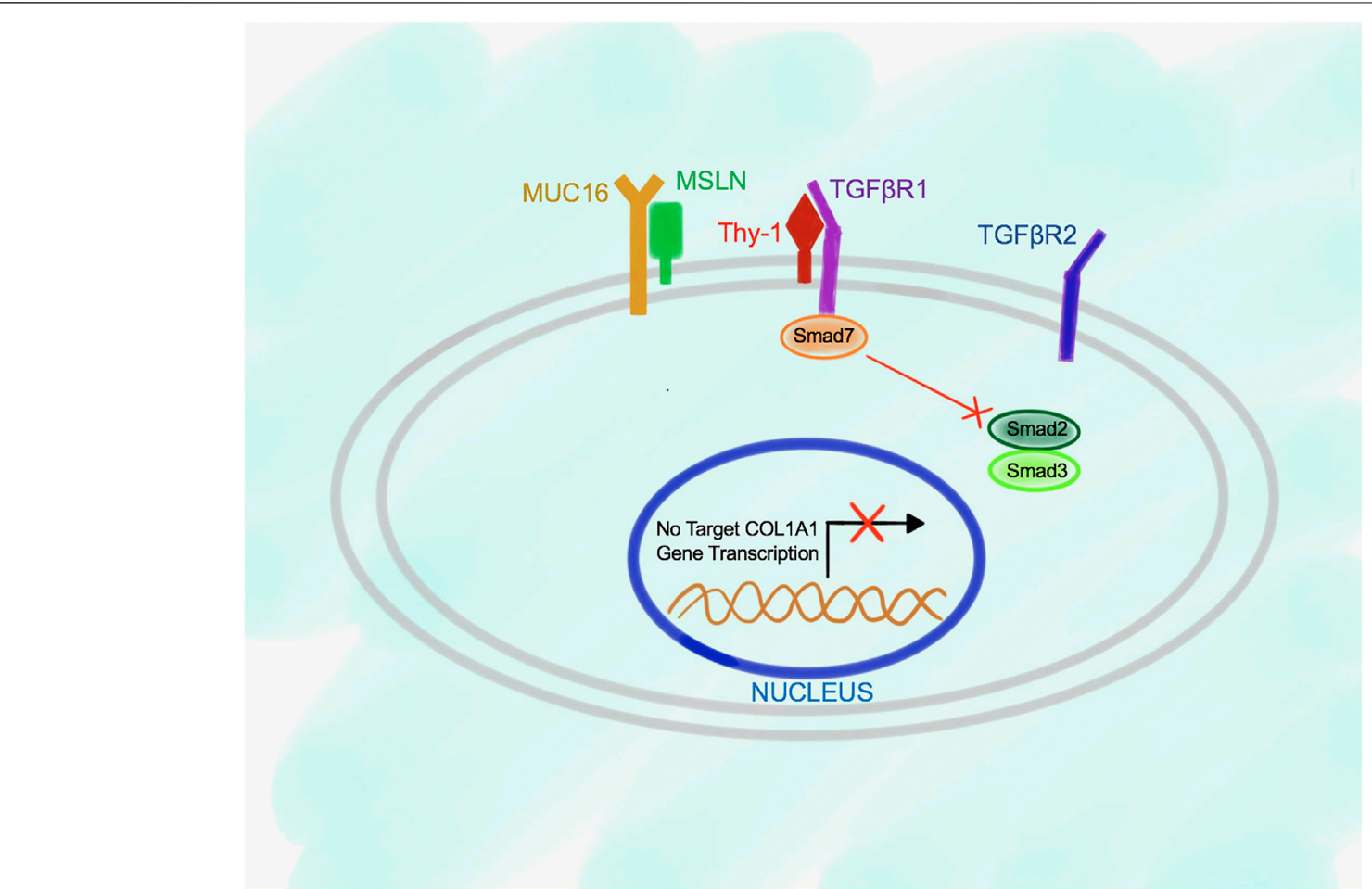

FIGURE 2 | Proposed model of MsIn-Muc16 and Thy-1-TGF $\beta$ RI binding in resting wild type aPFs. MsIn and Muc16 form a complex in resting aPFs. Thy-1 and TGF $\beta R$ I form a complex. Binding of Thy-1 to TGF $\beta R$ I prevents TGF $\beta 1$ signaling, and retains Smad7 at the C-terminus of the TGF $\beta R I$.

importance of Msln-Muc16 interaction. Moreover, ductular proliferation was reduced in cholestasis-injured $\mathrm{Msln}^{-/-} \mathrm{Mdr} 2^{-/-}$ mice and $\mathrm{Muc}^{-1-} \mathrm{Mdr}^{-/-}$mice, suggesting that aPF activation regulates cholangiocyte proliferation.

Thy $-1^{-/-}$mice are more susceptible to cholestatic fibrosis. Studies of the experimental models of cholestatic fibrosis in wild type, Msln ${ }^{-/-}$mice, Muc16 $6^{-/-}$mice, and Thy-1 $1^{-/-}$mice have demonstrated that Msln and Muc16 play pro-fibrogenic roles in aPF activation, while Thy-1 exhibits anti-fibrogenic properties. Consistently, cholestatic fibrosis is exacerbated in Thy-1 $1^{-/-}$mice. These findings were supported by in vitro comparison of primary isolated mouse wild type, $\mathrm{Msln}^{-/-}$, Muc16 $6^{-/-}$, and Thy-1 ${ }^{-/-}$aPFs. In resting aPFs, Thy-1 directly binds to TGF $\beta$ RI and blocks TGF $\beta 1$ binding to TGF $\beta R I$, thereby preventing TGF $\beta 1$ signaling.

\section{MSLN, MUC16 AND THY-1 REGULATE NON-CANONICAL TGF $\beta 1$-TGF $\beta$ RI SIGNALING IN CHOLESTASIS-ACTIVATED PORTAL FIBROBLASTS}

\section{Formation of Thy-1-TGF $\beta$ RI in Resting aPFs Prevents TGF $\beta 1$ Signaling}

The relationship between Msln, Muc16, Thy-1, and TGF $\beta$ RI receptors in the wild type and $\mathrm{Msln}^{-/-}$aPFs was established using immunoprecipitations (IPs) with specific antibodies against each molecule. Although not quantitative, this technique allowed to determine the dynamic changes in the protein binding between Msln, Muc16 and Thy-1 in the resting wild type aPFs and in response to TGF $\beta 1$ stimulation. We have demonstrated that in resting (serum starved) aPFs Thy1 makes an inhibitory complex with TGF $\beta$ RI receptor thereby preventing TGF $\beta 1$ binding to the $\mathrm{N}$-terminus of TGF $\beta$ RI. Thy-1 also binds to Muc16 but has minimal interaction with Msln (Figure 2). Meanwhile, Msln forms a strong complex with Muc16, suggesting that Muc16 transmits intracellular signals from Msln-Muc16 complex. TGF $\beta 1$ signaling is further inhibited by Smad7 (transcription factor implicated in suppression of TGF $\beta 1$ signaling), which is bound to the C-terminus of the TGF $\beta$ RI and prevents Smad2/3 docking and phosphorylation on TGF $\beta$ RI.

\section{TGF $\beta 1$ Signaling in aPFs Promotes Disruption of Thy-1-TGF $\beta$ RI Complex and Formation of MsIn-Muc16-Thy-1 Complex}

In turn, in response to stimulation of the wild type aPFs with TGF $\beta 1$, binding of TGF $\beta 1$ to TGF $\beta$ RI strongly increases the affinity of Msln to Thy-1 causing dissociation of Thy-1 from TGF $\beta$ RI (Figure 3). Formation of Msln-Muc16-Thy-1 complex results in disruption of Thy-1-TGF $\beta$ RI interaction and removal of Thy-1 from TGF $\beta$ RI. TGF $\beta$ I binds to TGF $\beta$ RI and TGF $\beta$ RII, causing dissociation of Smad7 from TGF $\beta$ RI and subsequent binding of Smad2/3 to the C-terminus of TGF $\beta$ RI where these transcription factors are phosphorylated and activated. 


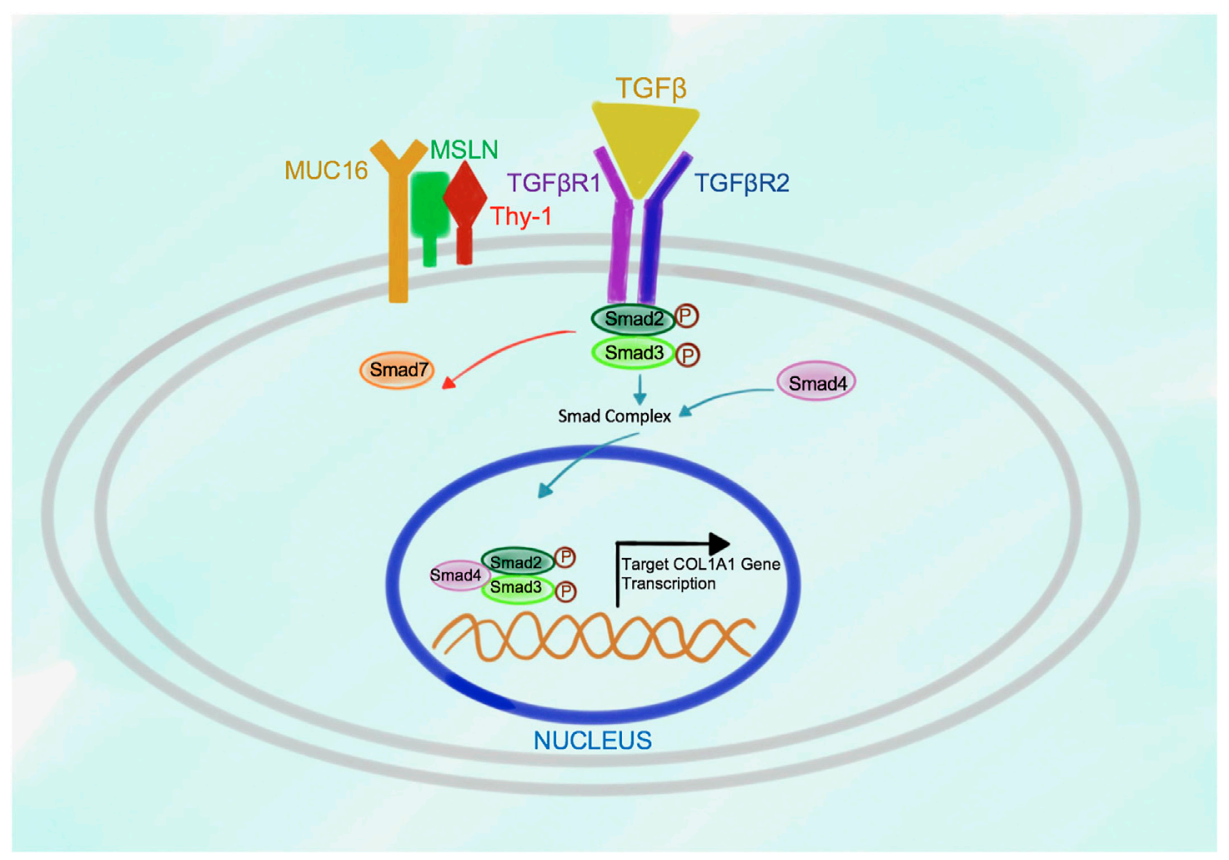

FIGURE 3 | Proposed model of MsIn-Muc16-Thy-1 binding in TGF $\beta 1$-stimulated wild type aPFs. In response to TGF $\beta 1$ signaling MsIn-Muc16 complex binds to Thy-1 causing dissociation of Thy-1 from TGF $\beta$ RI. TGF $\beta 1$ binding to TGF $\beta R$ I and TGF $\beta$ R2 causes receptor crosslinking, docking of Smad2/3 to the receptors. Upon Smad2/3 phosphorylation, $p$-Smad2/3 dissociates from the receptors, forms a complex with Smad4, and translocates to the nucleus where it initiates transcription of target genes.

FIGURE 4 | Proposed model of MsIn-Muc16-Thy-1-TGF $\beta R$ I signaling in MsIn ${ }^{-1-}$ aPFs. TGF $\beta 1$ signaling is impaired in Msln ${ }^{-1-}$ aPFs because Thy-1 forms a stable complex with TGF $\beta$ RI, which hinders TGF $\beta 1$ binding to TGF $\beta R I$ and TGF $\beta$ R2. Smad7 is bound to the cytoplasmic tail of TGF $\beta$ RI, thereby preventing docking and phosphorylation of Smad2/3. 
Phosphorylated Smad2/3 are released from TGF $\beta$ RI into the cytoplasm where they form a complex with Smad4. p-Smad2/ 3-Smad4 are translocated to the nucleus, where they bind to the DNA and initiate transcription of the fibrogenic genes, including Collagen Type I.

\section{TGF $\beta 1-T G F \beta R I$ Signaling is Suppressed in MsIn-Deficient aPFs}

Deletion of Msln results in suppression of TGF $\beta 1-T G F \beta R I$ signaling in aPFs due to increased Thy-1 expression, and higher affinity of Thy-1 binding to TGF $\beta$ RI (than in the wild type aPFs), indicating that Thy-1 serves as an inhibitory molecule for the TGF $\beta 1$ signaling in aPFs (Figure 4). Under these circumstances, Smad7 is constitutively bound to the C-terminus of TGF $\beta$ RI, suggesting that lack of Msln (or increased Thy-1-TGF $\beta 1 R I$ binding) promotes Smad7 docking to the cytoplasmic C-terminus of the TGF $\beta$ RI. As a result, activation and phosphorylation of $\operatorname{Smad} 2 / 3$ is reduced in $\mathrm{Msln}^{-/-}$aPFs; production of fibrogenic genes and Collagen Type I is suppressed.

\section{TGF $\beta 1-T G F \beta R I$ Signaling is Accelerated in Thy-1-Deficient aPFs}

Moreover, deletion of Thy-1 in aPFs results in strong overexpression of Msln in Thy- $1^{-/-}$aPFs, indicating that Thy-1 is a critical regulator of Msln. Indeed, Thy $-1^{-/-} \mathrm{aPFs}$ produce more Colla1 mRNA in response to TGF $\beta 1$ stimulation, and this effect is associated with increased phosphorylation of $\operatorname{Smad} 2 / 3$ and expression of TGF $\beta$ RI, while binding of Smad7 to TGF $\beta$ RI is decreased in Thy-1 $1^{-/-}$aPFs. We speculate that genetic deletion of Thy-1 gene results in exacerbation of Msln signaling caused by the compensatory overexpression of Msln and its target genes. It remains unknown if this effect can be solely attributed to the strong upregulation of Msln $(\approx 7$ fold over the wild type aPFs) in Thy $-1^{-/-}$aPFs, and/or the loss of Thy-1 functions (such as binding to TGF $\beta$ RI suppression of Msln expression). Since Thy-1 is a GPI-linked protein, Thy-1 might bind to another transmembrane signaling receptor (distinct from Muc16), or utilize the lipid rafts protein signaling to mediate its function.

\section{TGF $\beta 1$-TGF $\beta$ RI Signaling is Not Affected in Double Knockout MsIn ${ }^{-1-} \mathrm{Thy}^{-1^{-/-}}$aPFs}

Generation of double knockout $\mathrm{Msln}^{-/-} \mathrm{Thy}-1^{-/-}$aPFs revealed that Thy-1 and Msln might regulate one signaling pathway, since simultaneous deletion of Msln and Thy-1 abolished both phenotypes, and double knockout $\mathrm{Msln}^{-1-} \mathrm{Thy}^{-1^{-/}}$aPFs exhibited no obvious abnormalities. In support, simultaneous deletion of Msln and Thy-1 genes yielded a phenotype similar to that in the cholestasis-injured wild type mice, indicating that Msln and Thy-1 might regulate opposing functions within the same signaling pathway. These new findings suggest that MslnMuc16-Thy-1 signaling plays an important role in the regulation of TGF $\beta 1$-TGF $\beta$ RI signaling in cholestasis-activated aPFs.

\section{MSLN AS A TARGET FOR ANTI-FIBROTIC THERAPY}

\section{Thy $-1^{+}$and MsIn ${ }^{+}$aPFs are Expressed in Livers of Patients With Cholestatic Liver injury but not Toxic HCV Fibrosis}

When the composition of myofibroblasts was analyzed in livers of patients with liver fibrosis, the expression of MSLN and THY1 was upregulated in livers of PSC patients, patients with biliary atresia, and biliary cirrhosis (but not in livers of patients with HCV liver fibrosis). Expression of human THY-1 and MSLN correlated with the stage of cholestatic fibrosis, suggesting that $\mathrm{MSLN}^{+}$aPFs can be a novel target for anti-fibrotic therapy. Msln is widely expressed in embryonic mesothelium during mammalian development (Akira et al., 2006). In turn, Msln is minimally expressed in adult mice and healthy humans under physiological conditions. Upregulation of MSLN in adult humans is associated with cancer, and was recently linked to the development of cholestatic fibrosis (Pastan and Hassan, 2014).

\section{Potential Strategies to Target aPFs}

Historically high expression of MSLN was linked to increased tumor proliferation/invasion. Therefore, Msln serves as a target for anti-cancer therapy. We tested if targeting MSLN could also be beneficial for halting cholestatic fibrosis. Three classes of potential Msln inhibitors have been generated and potentially used to block MSLN-MUC16-THY-1 signaling pathway in patients: anti-human MSLN Ab-immunotoxin (that causes death of human MSLN $^{+}$cancer cells) (Hassan et al., 2007); anti-MSLN blocking Abs can potentially suppress growth and proliferation of aPFs (Onda et al., 2005); or recombinant human soluble THY1 (hsTHY1, that neutralize reactivity to $\alpha v-\beta 5$ integrins, and bind to TGF $\beta$ RI to prevent MSLN signaling) (Tan et al., 2019). These tools can potentially be used in patients with cholestatic fibrosis.

\section{Immunotherapy to Target Cancer Cells}

Immunotherapy-based strategy to target human cancer cells was developed by Dr. Pastan and colleagues, pioneers in the field of cancer research. Specifically, much progress has been made with immunotherapy-based therapeutics of human $\mathrm{MSLN}^{+}$ malignancies. MSLN is differentially expressed between normal and cancer cells, thus making it a strong candidate for anti-cancer therapy with recombinant immunotoxins (RITs) (Liu et al., 2012). Several generations of immunotoxins, such as SS1P and LMB100, were engineered by conjugation of anti-human MSLN SS1 Ab (Hassan et al., 2007; Hassan et al., 2014) to PE38 (truncated Pseudomo-nas exotoxin, that causes cellular apoptosis) (Hassan et al., 2000), and successfully tested in clinical trials in patients with mesothelioma, ovarian cancer and pancreatic cancer (Liu et al., 2012; Kreitman et al., 2009; Chowdhury and Pastan, 1999; Alewine et al., 2014))(https:// clinicaltrials.gov/ct2/show/NCT02810418) (Hassan et al., 2007; Hassan et al., 2014; Kreitman et al., 2009). In detail, SS1(dsFv) PE38 (SS1P) is a RIT that consists of a modified bacterial toxin 
Pseudomonas exotoxin A (PE38) that is bound to the anti-MSLN $\mathrm{Ab}(\mathrm{SS} 1(\mathrm{dsFv}))$ directed against the MSLN antigen expressed on the surface of the target cells (Chowdhury and Pastan, 1999). Once bound to MSLN, the entire RIT molecule is internalized, leading to the release of PE38 into the cytosol and cellular apoptosis via inactivation of ADP-ribosylation/elongation factor 2 pathway (Hassan et al., 2000; Pastan et al., 2007).

\section{Targeting Msln ${ }^{+}$aPFs With immunotoxins as Potential Strategy for Treatment of Cholestatic Fibrosis}

The question remains if a similar strategy can be used to ablate aPFs to eliminate the source of Collagen Type I. Based on our previous findings in mice, genetic ablation of aPFs (using overexpression of Diphtheria Toxin a, DTA) causes aPF apoptosis without causing structural liver damage, and attenuates development of cholestatic fibrosis in BDL-injured mice (Koyama et al., 2017), outlining that immunotoxin-based ablation of human aPFs may become a novel strategy for treatment of PSC patients. In accord, SV40-Large SS1P and LMB100 immunotoxins (Hassan et al., 2007) can successfully kill human primary cultured aPFs in vitro, but also in vivo in the xenograft mice, generated by adoptive transplantation of human primary aPFs into the livers of adult immunodeficient Rag2 $2^{-/-}$ $\mathrm{\gamma c}^{-/-}$mice (Nishio et al., 2021). Generation of "human aPF xenograft" Rag2 $2^{-/-} \gamma \mathrm{c}^{-/-}$mice is novel, and might serve as a useful model to study in vivo the variability of patient-specific responses of human aPFs (fibrogenic activation/proliferation) to specific MSLN inhibitors (Nishio et al., 2021).

A potential drawback is that repeated administration of RITs (Kreitman et al., 2009) might lead to the formation of anti-drug antibodies (ADAs) and accelerated clearance of anti-MSLNimmunotoxins (Baker et al., 2010). LMB100 was engineered to reduce immunogenicity in humans compared with SS1P (Liu et al., 2012; Alewine et al., 2014). Both immunotoxins successfully showed excellent anti-tumor activity in clinical trials in patients with mesothelioma, ovarian and pancreatic cancer (Kreitman et al., 2009; Hassan et al., 2014).

\section{Blocking of MsIn Expression in aPFs May Attenuate Cholestatic Liver Fibrosis}

Administration of blocking unconjugated anti-Msln As (Koyama et al., 2017) might also be beneficial in suppression of aPF proliferation and activation. Such strategy was explored in BDL-injured mice, and repetitive administration of Mslnblocking Abs (D233-3, 5ng, $10 \mathrm{ng}, \mathrm{MBL}$ Inc.; or B35 Ab, $10 \mathrm{ng}$, LSBio) was shown to inhibit aPFs and reduced cholestatic fibrosis.

\section{Human Soluble hsTHY-1-Fc Peptide}

THY-1 exhibits anti-fibrogenic properties. Human soluble THY1 peptide shares high similarity with mouse soluble Thy-1 and crossreacts with mouse ligands. Binding of hsTHY-1 (but not hsTHY-1-RLE with mutated integrin-binding RGD-like motif)
(Tan et al., 2019) to $\alpha v \beta 5$ integrin was shown to prevent activation of latent TGF $\beta 1$ in lung fibroblasts (Zhou et al., 2010). Based on our unpublished observation, administration of hsTHY-1 peptide $(1 \mu \mathrm{g} / \mathrm{g}$ in PBS) suppressed BDL-induced aPF activation in BDL-injured mice and attenuated development of cholestatic fibrosis (compared to mutant hsTHY-1-RLE- or vehicle-treated mice). We can speculate that administration of hsTHY-1 also prevents TBF $\beta 1-T G F \beta R I$ signaling.

\section{CONCLUSION}

Investigation of the role of Msln, Muc16, and Thy1 in cholestatic fibrosis revealed that $\mathrm{Msln}^{-/-}$mice are protected from cholestatic fibrosis caused by Mdr2 deficiency, or BDL-induced obstruction of the common bile duct. There is a growing evidence that Msln is a critical activator of aPFs. Msln expression correlates with the stage of liver fibrosis in patients with PSC. Anti-MSLN Abimmunotoxins, developed for cancer therapy, can potentially be used to target human $\mathrm{MSLN}^{+}$aPFs for treatment of cholestatic fibrosis. Overall, immunotherapy-based ablation of human aPFs might become a novel strategy for treatment of cholestatic fibrosis. It might not cure patients with cholestatic fibrosis but can decrease fibroproliferative responses to bridge PSC patients to liver transplantation, or treatment of the etiological causes.

\section{AUTHOR CONTRIBUTIONS}

HF and GM wrote the manuscript. TN, YK, KL, VZ helped with the manuscript preparation. RL and $\mathrm{DB}$ critically revised the manuscript. TK wrote the manuscript and provided support.

\section{FUNDING}

Supported by the National Institutes of Health R01DK101737, U01AA022614, R01DK099205, R01DK111866, R01AA028550, P50AA011999, U01AA018663, P30 DK120515, 5U01AA029019, R01DK091183, R01DK09920 (TK), P42ES010337 and fR44DK115242 (DB). GM, KL and VZ received funding support from Lee Summer Research Fellowship 2018, Southern California Research Center for ALPD and Cirrhosis. RL receives funding support from NIEHS (5P42ES010337), NCATS (5UL1TR001442), DOD PRCRP (W81XWH-18-20026), NIDDK (U01DK061734, R01DK106419, R01DK121378, R01DK124318, P30DK120515), NHLBI (P01HL147835), and NIAAA (U01AA029019).

\section{ACKNOWLEDGMENTS}

We thank Ms. Karin Diggle for excellent technical assistance (University of California, San Diego, La Jolla, CA, United States) for help with the ms editing. 


\section{REFERENCES}

Akira, S., Uematsu, S., and Takeuchi, O. (2006). Pathogen Recognition and Innate Immunity. Cell 124 (4), 783-801. doi:10.1016/j.cell.2006.02.015

Alewine, C., Xiang, L., Yamori, T., Niederfellner, G., Bosslet, K., and Pastan, I. (2014). Efficacy of RG7787, a Next-Generation Mesothelin-Targeted Immunotoxin, against Triple-Negative Breast and Gastric Cancers. Mol. Cancer Ther. 13 (11), 2653-2661. doi:10.1158/1535-7163.MCT-14-0132

Asahina, K. (2012). Hepatic Stellate Cell Progenitor Cells. J. Gastroenterol. Hepatol. 27 (Suppl. 2), 80-84. doi:10.1111/j.1440-1746.2011.07001.x

Asahina, K., Tsai, S. Y., Li, P., Ishii, M., Maxson, R. E., Jr., Sucov, H. M., et al. (2009). Mesenchymal Origin of Hepatic Stellate Cells, Submesothelial Cells, and Perivascular Mesenchymal Cells during Mouse Liver Development. Hepatology 49 (3), 998-1011. doi:10.1002/hep.22721

Asahina, K., Zhou, B., Pu, W. T., and Tsukamoto, H. (2011). Septum TransversumDerived Mesothelium Gives Rise to Hepatic Stellate Cells and Perivascular Mesenchymal Cells in Developing Mouse Liver. Hepatology 53 (3), 983-995. doi:10.1002/hep.24119

Baghdasaryan, A., Claudel, T., Kosters, A., Gumhold, J., Silbert, D., Thuringer, A., et al. (2010). Curcumin Improves Sclerosing Cholangitis in Mdr2-/- Mice by Inhibition of Cholangiocyte Inflammatory Response and portal Myofibroblast Proliferation. Gut 59 (4), 521-530. doi:10.1136/gut.2009.186528

Baker, M., Reynolds, H. M., Lumicisi, B., and Bryson, C. J. (2010). Immunogenicity of Protein Therapeutics: The Key Causes, Consequences and Challenges. Self/ Nonself 1 (4), 314-322. doi:10.4161/self.1.4.13904

Bataller, R., and Brenner, D. A. (2005). Liver Fibrosis. J. Clin. Invest. 115 (2), 209-218. doi:10.1172/JCI24282

Bera, T. K., and Pastan, I. (2000). Mesothelin Is Not Required for normal Mouse Development or Reproduction. Mol. Cell Biol 20 (8), 2902-2906. doi:10.1128/ mcb.20.8.2902-2906.2000

Bochmann, L., Sarathchandra, P., Mori, F., Lara-Pezzi, E., Lazzaro, D., and Rosenthal, N. (2010). Revealing New Mouse Epicardial Cell Markers through Transcriptomics. PLoS One 5 (6), el1429. doi:10.1371/ journal.pone.0011429

Bosselut, N., Housset, C., Marcelo, P., Rey, C., Burmester, T., Vinh, J., et al. (2010). Distinct Proteomic Features of Two Fibrogenic Liver Cell Populations: Hepatic Stellate Cells and portal Myofibroblasts. Proteomics 10 (5), 1017-1028. doi:10.1002/pmic.200900257

Bradley, J. E., Ramirez, G., and Hagood, J. S. (2009). Roles and Regulation of Thy-1, a Context-dependent Modulator of Cell Phenotype. Biofactors 35 (3), 258-265. doi:10.1002/biof.41

Chang, K., and Pastan, I. (1996). Molecular Cloning of Mesothelin, a Differentiation Antigen Present on Mesothelium, Mesotheliomas, and Ovarian Cancers. Proc. Natl. Acad. Sci. 93 (1), 136-140. doi:10.1073/ pnas.93.1.136

Cheung, A. C., Lorenzo Pisarello, M. J., and LaRusso, N. F. (2018). Pathobiology of Biliary Epithelia. Biochim. Biophys. Acta (Bba) - Mol. Basis Dis. 1864 (4 Pt B), 1220-1231. doi:10.1016/j.bbadis.2017.06.024

Chowdhury, P. S., and Pastan, I. (1999). Improving Antibody Affinity by Mimicking Somatic Hypermutation In Vitro. Nat. Biotechnol. 17 (6), 568-572. doi:10.1038/9872

Chu, A. S., Diaz, R., Hui, J.-J., Yanger, K., Zong, Y., Alpini, G., et al. (2011). Lineage Tracing Demonstrates No Evidence of Cholangiocyte Epithelial-ToMesenchymal Transition in Murine Models of Hepatic Fibrosis. Hepatology 53 (5), 1685-1695. doi:10.1002/hep.24206

Desmoulière, A., Darby, I., Costa, A. M., Raccurt, M., Tuchweber, B., Sommer, P., et al. (1997). Extracellular Matrix Deposition, Lysyl Oxidase Expression, and Myofibroblastic Differentiation during the Initial Stages of Cholestatic Fibrosis in the Rat. Lab. Invest. 76 (6), 765-778.

Desmoulière, A. (2007). Hepatic Stellate Cells: the Only Cells Involved in Liver Fibrogenesis? A Dogma Challenged. Gastroenterology 132 (5), 2059-2062. doi:10.1053/j.gastro.2007.03.075

Dranoff, J. A., Kruglov, E. A., Robson, S. C., Braun, N., Zimmermann, H., and Sévigny, J. (2002). The Ecto-Nucleoside Triphosphate Diphosphohydrolase NTPDase2/CD39L1 Is Expressed in a Novel Functional Compartment within the Liver. Hepatology 36 (5), 1135-1144. doi:10.1053/ jhep.2002.36823
Dranoff, J. A., and Wells, R. G. (2010). Portal Fibroblasts: Underappreciated Mediators of Biliary Fibrosis. Hepatology 51 (4), 1438-1444. doi:10.1002/ hep. 23405

Dudas, J., Mansuroglu, T., Batusic, D., Saile, B., and Ramadori, G. (2007). Thy-1 Is an In Vivo and In Vitro Marker of Liver Myofibroblasts. Cell Tissue Res 329 (3), 503-514. doi:10.1007/s00441-007-0437-z

Eyden, B. (2008). The Myofibroblast: Phenotypic Characterization as a Prerequisite to Understanding its Functions in Translational Medicine. J. Cell Mol Med 12 (1), 22-37. doi:10.1111/j.1582-4934.2007.00213.x

Fallowfield, J. A., Mizuno, M., Kendall, T. J., Constandinou, C. M., Benyon, R. C., Duffield, J. S., et al. (2007). Scar-associated Macrophages Are a Major Source of Hepatic Matrix Metalloproteinase-13 and Facilitate the Resolution of Murine Hepatic Fibrosis. J. Immunol. 178 (8), 5288-5295. doi:10.4049/ jimmunol.178.8.5288

Fausther, M., and Dranoff, J. A. (2011). New Insights on the Pathogenesis of Biliary Cirrhosis provided by Studies in FXR Knockout Mice. J. Hepatol. 55 (4), 939-940. doi:10.1016/j.jhep.2011.04.013

Fickert, P., Fuchsbichler, A., Moustafa, T., Wagner, M., Zollner, G., Halilbasic, E., et al. (2009). Farnesoid X Receptor Critically Determines the Fibrotic Response in Mice but Is Expressed to a Low Extent in Human Hepatic Stellate Cells and Periductal Myofibroblasts. Am. J. Pathol. 175 (6), 2392-2405. doi:10.2353/ ajpath.2009.090114

Fickert, P., Fuchsbichler, A., Wagner, M., Zollner, G., Kaser, A., Tilg, H., et al. (2004). Regurgitation of Bile Acids from Leaky Bile Ducts Causes Sclerosing Cholangitis in Mdr2 (Abcb4) Knockout Mice. Gastroenterology 127 (1), 261-274. doi:10.1053/j.gastro.2004.04.009

Fickert, P., Zollner, G., Fuchsbichler, A., Stumptner, C., Weiglein, A. H., Lammert, F., et al. (2002). Ursodeoxycholic Acid Aggravates Bile Infarcts in Bile DuctLigated and Mdr2 Knockout Mice via Disruption of Cholangioles. Gastroenterology 123 (4), 1238-1251. doi:10.1053/gast.2002.35948

Fiore, V. F., Strane, P. W., Bryksin, A. V., White, E. S., Hagood, J. S., and Barker, T. H. (2015). Conformational Coupling of Integrin and Thy-1 Regulates Fyn Priming and Fibroblast Mechanotransduction. J. Cell Biol 211 (1), 173-190. doi:10.1083/jcb.201505007

Forbes, S. J., and Parola, M. (2011). Liver Fibrogenic Cells. Best Pract. Res. Clin. Gastroenterol. 25 (2), 207-217. doi:10.1016/j.bpg.2011.02.006

Friedman, S. L. (2008). Mechanisms of Hepatic Fibrogenesis. Gastroenterology 134 (6), 1655-1669. doi:10.1053/j.gastro.2008.03.003

Gabbiani, G., Ryan, G. B., and Majno, G. (1971). Presence of Modified Fibroblasts in Granulation Tissue and Their Possible Role in Wound Contraction Experientia 27 (5), 549-550. doi:10.1007/bf02147594

Geerts, A. (2001). History, Heterogeneity, Developmental Biology, and Functions of Quiescent Hepatic Stellate Cells. Semin. Liver Dis. 21 (3), 311-336. doi:10.1055/s-2001-17550

Goodpaster, T., Legesse-Miller, A., Hameed, M. R., Aisner, S. C., RandolphHabecker, J., and Coller, H. A. (2008). An Immunohistochemical Method for Identifying Fibroblasts in Formalin-Fixed, Paraffin-Embedded Tissue. J. Histochem. Cytochem. 56 (4), 347-358. doi:10.1369/jhc.7a7287.2007

Gubbels, J. A., Belisle, J., Onda, M., Rancourt, C., Migneault, M., Ho, M., et al. (2006). Mesothelin-MUC16 Binding Is a High Affinity, N-Glycan Dependent Interaction that Facilitates Peritoneal Metastasis of Ovarian Tumors. Mol. Cancer 5 (1), 50. doi:10.1186/1476-4598-5-50

Hagood, J. S., Guo, B. L., Nesbitt, J. E., and Lasky, J. A. (1999). Differential Expression and Secretion of Connective Tissue Growth Factor by Lung Fibroblast Subpopulations. Am. J. Respir. Crit. Care Med. 159 (3 Part 2), A195.

Hagood, J. S., Prabhakaran, P., Kumbla, P., Salazar, L., MacEwen, M. W., Barker, T. H., et al. (2005). Loss of Fibroblast Thy-1 Expression Correlates with Lung Fibrogenesis. Am. J. Pathol. 167 (2), 365-379. doi:10.1016/s0002-9440(10) 62982-3

Hassan, R., Bullock, S., Premkumar, A., Kreitman, R. J., Kindler, H., Willingham, M. C., et al. (2007). Phase I Study of SS1P, a Recombinant Anti-mesothelin Immunotoxin Given as a Bolus I.V. Infusion to Patients with MesothelinExpressing Mesothelioma, Ovarian, and Pancreatic Cancers. Clin. Cancer Res. 13 (17), 5144-5149. doi:10.1158/1078-0432.CCR-07-0869

Hassan, R., Sharon, E., Thomas, A., Zhang, J., Ling, A., Miettinen, M., et al. (2014). Phase 1 Study of the Antimesothelin Immunotoxin SS1P in Combination with Pemetrexed and Cisplatin for Front-Line Therapy of Pleural Mesothelioma and Correlation of Tumor Response with Serum Mesothelin, Megakaryocyte 
Potentiating Factor, and Cancer Antigen. Cancer 120 (21), 3311-3319. doi:10.1002/cncr.28875

Hassan, R., Viner, J. L., Wang, Q.-C., Margulies, I., Kreitman, R. J., and Pastan, I. (2000). Anti-tumor Activity of K1-LysPE38QQR, an Immunotoxin Targeting Mesothelin, a Cell-Surface Antigen Overexpressed in Ovarian Cancer and Malignant Mesothelioma. J. Immunother. 23 (4), 473-479. doi:10.1097/ 00002371-200007000-00011

He, X., Wang, L., Riedel, H., Wang, K., Yang, Y., Dinu, C. Z., et al. (2017). Mesothelin Promotes Epithelial-To-Mesenchymal Transition and Tumorigenicity of Human Lung Cancer and Mesothelioma Cells. Mol. Cancer 16 (1), 63. doi:10.1186/s12943-017-0633-8

Iredale, J. P. (2007). Models of Liver Fibrosis: Exploring the Dynamic Nature of Inflammation and Repair in a Solid Organ. J. Clin. Invest. 117 (3), 539-548. doi:10.1172/jci30542

Iwaisako, K., Jiang, C., Zhang, M., Cong, M., Moore-Morris, T. J., Park, T. J., et al. (2014). Origin of Myofibroblasts in the Fibrotic Liver in Mice. Proc. Natl. Acad. Sci. 111 (32), E3297-E3305. doi:10.1073/pnas.1400062111

Jacquemin, E. (2001). Role of Multidrug Resistance 3 Deficiency in Pediatric and Adult Liver Disease: One Gene for Three Diseases. Semin. Liver Dis. 21 (4), 551-562. doi:10.1055/s-2001-19033

Kaneko, O., Gong, L., Zhang, J., Hansen, J. K., Hassan, R., Lee, B., et al. (2009). A Binding Domain on Mesothelin for CA125/MUC16. J. Biol. Chem. 284 (6), 3739-3749. doi:10.1074/jbc.M806776200

Karin, D., Koyama, Y., Brenner, D., and Kisseleva, T. (2016). The Characteristics of Activated portal Fibroblasts/myofibroblasts in Liver Fibrosis. Differentiation 92 (3), 84-92. doi:10.1016/j.diff.2016.07.001

Katsumata, L. W., Miyajima, A., and Itoh, T. (2017). Portal Fibroblasts Marked by the Surface Antigen Thyl Contribute to Fibrosis in Mouse Models of Cholestatic Liver Injury. Hepatol. Commun. 1 (3), 198-214. doi:10.1002/ hep4.1023

Kawada, N., Kristensen, D. B., Asahina, K., Nakatani, K., Minamiyama, Y., Seki, S., et al. (2001). Characterization of a Stellate Cell Activation-Associated Protein (STAP) with Peroxidase Activity Found in Rat Hepatic Stellate Cells. J. Biol. Chem. 276 (27), 25318-25323. doi:10.1074/jbc.M102630200

Kendall, T. J., Hennedige, S., Aucott, R. L., Hartland, S. N., Vernon, M. A., Benyon, R. C., et al. (2009). p75 Neurotrophin Receptor Signaling Regulates Hepatic Myofibroblast Proliferation and Apoptosis in Recovery from Rodent Liver Fibrosis. Hepatology 49 (3), 901-910. doi:10.1002/hep.22701

Kisseleva, T., and Brenner, D. A. (2006). Hepatic Stellate Cells and the Reversal of Fibrosis. J. Gastroenterol. Hepatol. 21 (Suppl. 3), S84-S87. doi:10.1111/j.14401746.2006.04584.x

Kisseleva, T., Uchinami, H., Feirt, N., Quintana-Bustamante, O., Segovia, J. C., Schwabe, R. F., et al. (2006). Bone Marrow-Derived Fibrocytes Participate in Pathogenesis of Liver Fibrosis. J. Hepatol. 45 (3), 429-438. doi:10.1016/ j.jhep.2006.04.014

Knittel, T., Kobold, D., Saile, B., Grundmann, A., Neubauer, K., Piscaglia, F., et al. (1999). Rat Liver Myofibroblasts and Hepatic Stellate Cells: Different Cell Populations of the Fibroblast Lineage with Fibrogenic Potential. Gastroenterology 117 (5), 1205-1221. doi:10.1016/s0016-5085(99)70407-5

Koyama, Y., Wang, P., Liang, S., Iwaisako, K., Liu, X., Xu, J., et al. (2017). Mesothelin/mucin 16 Signaling in Activated portal Fibroblasts Regulates Cholestatic Liver Fibrosis. J. Clin. Invest. 127 (4), 1254-1270. doi:10.1172/ JCI88845

Kreitman, R. J., Hassan, R., Fitzgerald, D. J., and Pastan, I. (2009). Phase I Trial of Continuous Infusion Anti-mesothelin Recombinant Immunotoxin SS1P. Clin. Cancer Res. 15 (16), 5274-5279. doi:10.1158/1078-0432.CCR-09-0062

Kruglov, E. A., Jain, D., and Dranoff, J. A. (2002). Isolation of Primary Rat Liver Fibroblasts. J. Invest. Med. 50 (3), 179-184. doi:10.2310/6650.2002.33431

Lazaridis, K. N., and LaRusso, N. F. (2016). Primary Sclerosing Cholangitis. N. Engl. J. Med. 375 (25), 2501-2502. doi:10.1056/NEJMc1613273

Liu, W., Onda, M., Lee, B., Kreitman, R. J., Hassan, R., Xiang, L., et al. (2012). Recombinant Immunotoxin Engineered for Low Immunogenicity and Antigenicity by Identifying and Silencing Human B-Cell Epitopes. Proc. Natl. Acad. Sci. 109 (29), 11782-11787. doi:10.1073/pnas.1209292109

Mair, M., Zollner, G., Schneller, D., Musteanu, M., Fickert, P., Gumhold, J., et al. (2010). Signal Transducer and Activator of Transcription 3 Protects from Liver Injury and Fibrosis in a Mouse Model of Sclerosing Cholangitis. Gastroenterology 138 (7), 2499-2508. doi:10.1053/j.gastro.2010.02.049
Majno, G., Gabbiani, G., Hirschel, B. J., Ryan, G. B., and Statkov, P. R. (1971). Contraction of Granulation Tissue In Vitro: Similarity to Smooth Muscle. Science 173 (996), 548-550. doi:10.1126/science.173.3996.548

McIntosh, J. C., Hagood, J. S., Richardson, T. L., and Simecka, J. W. (1994). Thy1 $(+)$ and (-) Lung Fibrosis Subpopulations in LEW and F344 Rats. Eur. Respir. J. 7 (12), 2131-2138. doi:10.1183/09031936.94.07122131

McMullen, M. R., Pritchard, M. T., Wang, Q., Millward, C. A., Croniger, C. M., and Nagy, L. E. (2005). Early Growth Response-1 Transcription Factor Is Essential for Ethanol-Induced Fatty Liver Injury in Mice. Gastroenterology 128 (7), 2066-2076. doi:10.1053/j.gastro.2005.02.065

Mederacke, I., Hsu, C. C., Troeger, J. S., Huebener, P., Mu, X., Dapito, D. H., et al. (2013). Fate Tracing Reveals Hepatic Stellate Cells as Dominant Contributors to Liver Fibrosis Independent of its Aetiology. Nat. Commun. 4, 2823. doi:10.1038/ ncomms 3823

Nishio, T., Koyama, Y., Liu, X., Rosenthal, S. B., Yamamoto, G., Fuji, H., et al. (2021). Immunotherapy-based Targeting of MSLN+ Activated portal Fibroblasts Is a Strategy for Treatment of Cholestatic Liver Fibrosis. Proc. Natl. Acad. Sci. USA 118 (29), e2101270118. doi:10.1073/pnas.2101270118

Nosten-Bertrand, M., Errington, M. L., Murphy, K. P. S. J., Tokugawa, Y., Barboni, E., Kozlova, E., et al. (1996). Normal Spatial Learning Despite Regional Inhibition of LTP in Mice Lacking Thy-1. Nature 379 (6568), 826-829. doi:10.1038/379826a0

Onda, M., Willingham, M., Nagata, S., Bera, T. K., Beers, R., Ho, M., et al. (2005). New Monoclonal Antibodies to Mesothelin Useful for Immunohistochemistry, Fluorescence-Activated Cell Sorting, Western Blotting, and ELISA. Clin. Cancer Res. 11 (16), 5840-5846. doi:10.1158/1078-0432.CCR-05-0578

Onitsuka, I., Tanaka, M., and Miyajima, A. (2010). Characterization and Functional Analyses of Hepatic Mesothelial Cells in Mouse Liver Development. Gastroenterology 138 (4), 1525-1535. doi:10.1053/ j.gastro.2009.12.059

Pastan, I., and Hassan, R. (2014). Discovery of Mesothelin and Exploiting it as a Target for Immunotherapy. Cancer Res. 74 (11), 2907-2912. doi:10.1158/00085472.CAN-14-0337

Pastan, I., Hassan, R., FitzGerald, D. J., and Kreitman, R. J. (2007). Immunotoxin Treatment of Cancer. Annu. Rev. Med. 58, 221-237. doi:10.1146/ annurev.med.58.070605.115320

Popov, Y., Patsenker, E., Fickert, P., Trauner, M., and Schuppan, D. (2005). Mdr2 (Abcb4)-/- Mice Spontaneously Develop Severe Biliary Fibrosis via Massive Dysregulation of Pro- and Antifibrogenic Genes. J. Hepatol. 43 (6), 1045-1054. doi:10.1016/j.jhep.2005.06.025

Ramírez, G., Hagood, J. S., Sanders, Y., Ramírez, R., Becerril, C., Segura, L., et al. (2011). Absence of Thy-1 Results in TGF- $\beta$ Induced MMP-9 Expression and Confers a Profibrotic Phenotype to Human Lung Fibroblasts. Lab. Invest. 91 (8), 1206-1218. doi:10.1038/labinvest.2011.80

Sachs, B. D., Baillie, G. S., McCall, J. R., Passino, M. A., Schachtrup, C., Wallace, D. A., et al. (2007). p75 Neurotrophin Receptor Regulates Tissue Fibrosis through Inhibition of Plasminogen Activation via a PDE4/cAMP/PKA Pathway. J. Cell Biol 177 (6), 1119-1132. doi:10.1083/jcb.200701040

Sanders, Y. Y., Kumbla, P., and Hagood, J. S. (2007). Enhanced Myofibroblastic Differentiation and Survival in Thy-1(-) Lung Fibroblasts. Am. J. Respir. Cell Mol Biol 36 (2), 226-235. doi:10.1165/rcmb.2006-0178OC

Scholler, N., and Urban, N. (2007). CA125 in Ovarian Cancer. Biomarkers Med. 1 (4), 513-523. doi:10.2217/17520363.1.4.513

Scholten, D., Österreicher, C. H., Scholten, A., Iwaisako, K., Gu, G., Brenner, D. A., et al. (2010). Genetic Labeling Does Not Detect Epithelial-To-Mesenchymal Transition of Cholangiocytes in Liver Fibrosis in Mice. Gastroenterology 139 (3), 987-998. doi:10.1053/j.gastro.2010.05.005

Scholten, D., Reichart, D., Paik, Y. H., Lindert, J., Bhattacharya, J., Glass, C. K., et al. (2011). Migration of Fibrocytes in Fibrogenic Liver Injury. Am. J. Pathol. 179 (1), 189-198. doi:10.1016/j.ajpath.2011.03.049

Schürch, W., Seemayer, T. A., and Gabbiani, G. (1998). The Myofibroblast: a Quarter century after its Discovery. Am. J. Surg. Pathol. 22 (2), 141-147. doi:10.1097/00000478-199802000-00001

Senoo, H., Kojima, N., and Sato, M. (2007). Vitamin A-Storing Cells (Stellate Cells). Vitam Horm. 75, 131-159. doi:10.1016/s0083-6729(06)75006-3

Smit, J. J. M., Schinkel, A. H., Elferink, R. P. J. O., Groen, A. K., Wagenaar, E., van Deemter, L., et al. (1993). Homozygous Disruption of the Murine Mdr2 P-Glycoprotein Gene Leads to a Complete Absence of Phospholipid 
from Bile and to Liver Disease. Cell 75 (3), 451-462. doi:10.1016/0092-8674(93) 90380-9

Sueblinvong, V., Neujahr, D. C., Todd Mills, S., Roser-Page, S., Guidot, D., Rojas, M., et al. (2012). Predisposition for Disrepair in the Aged Lung. Am. J. Med. Sci. 344 (1), 41-51. doi:10.1097/maj.0b013e318234c132

Tan, C., Jiang, M., Wong, S. S., Espinoza, C. R., Kim, C., Li, X., et al. (2019). Soluble Thy-1 Reverses Lung Fibrosis via its Integrin-Binding Motif. JCI Insight 4 (21), e131152. doi:10.1172/jci.insight.131152

Taura, K., Miura, K., Iwaisako, K., Österreicher, C. H., Kodama, Y., PenzÖsterreicher, M., et al. (2010). Hepatocytes Do Not Undergo EpithelialMesenchymal Transition in Liver Fibrosis in Mice. Hepatology 51 (3), 1027-1036. doi:10.1002/hep.23368

Uchio, K., Tuchweber, B., Manabe, N., Gabbiani, G., Rosenbaum, J., and Desmoulière, A. (2002). Cellular Retinol-Binding Protein-1 Expression and Modulation during In Vivo and In Vitro Myofibroblastic Differentiation of Rat Hepatic Stellate Cells and portal Fibroblasts. Lab. Invest. 82 (5), 619-628. doi:10.1038/labinvest.3780456

Vavassori, P., Mencarelli, A., Renga, B., Distrutti, E., and Fiorucci, S. (2009). The Bile Acid Receptor FXR Is a Modulator of Intestinal Innate Immunity. J. Immunol. 183 (10), 6251-6261. doi:10.4049/jimmunol.0803978

Wagner, M., Zollner, G., and Trauner, M. (2010). Nuclear Receptor Regulation of the Adaptive Response of Bile Acid Transporters in Cholestasis. Semin. Liver Dis. 30 (2), 160-177. doi:10.1055/s-0030-1253225

Wells, R. G. (2014). The portal Fibroblast: Not Just a Poor Man's Stellate Cell. Gastroenterology 147 (1), 41-47. doi:10.1053/j.gastro.2014.05.001

Wen, J. W., Olsen, A. L., Perepelyuk, M., and Wells, R. G. (2012). Isolation of Rat portal Fibroblasts by In Situ Liver Perfusion. JoVE 64 (64), 3669. doi:10.3791/ 3669

Yata, Y., Scanga, A., Gillan, A., Yang, L., Reif, S., Breindl, M., et al. (2003). DNase I-Hypersensitive Sites Enhance al(I) Collagen Gene Expression in Hepatic Stellate Cells. Hepatology 37 (2), 267-276. doi:10.1053/ jhep.2003.50067

Yovchev, M. I., Zhang, J., Neufeld, D. S., Grozdanov, P. N., and Dabeva, M. D. (2009). Thymus Cell Antigen-1-Expressing Cells in the Oval Cell Compartment. Hepatology 50 (2), 601-611. doi:10.1002/hep.23012

Zhang, D., Kobayashi, T., Kojima, T., Kanenishi, K., Hagiwara, Y., Abe, M., et al. (2011). Deficiency of the Erc/mesothelin Gene Ameliorates Renal
Carcinogenesis in Tsc2 Knockout Mice. Cancer Sci. 102 (4), 720-727. doi:10.1111/j.1349-7006.2011.01846.x

Zhou, Y., Hagood, J. S., Lu, B., Merryman, W. D., and Murphy-Ullrich, J. E. (2010). Thy-1-Integrin av $\beta 5$ Interactions Inhibit Lung Fibroblast Contraction-Induced Latent Transforming Growth Factor- $\beta 1$ Activation and Myofibroblast Differentiation. J. Biol. Chem. 285 (29), 22382-22393. doi:10.1074/ jbc.M110.126227

Conflict of Interest: RL serves as a consultant for Aardvark Therapeutics, Altimmune, Anylam/Regeneron, Amgen, Arrowhead Pharmaceuticals, AstraZeneca, Bristol-Myer Squibb, CohBar, Eli Lilly, Galmed, Gilead, Glympse bio, Hightide, Inipharm, Intercept, Inventiva, Ionis, Janssen Inc., Madrigal, Metacrine, Inc., NGM Biopharmaceuticals, Novartis, Novo Nordisk, Merck, Pfizer, Sagimet, Theratechnologies, 89 bio, and Viking Therapeutics. In addition, his institution has received grant support from Allergan, Astrazeneca, Boehringer-Ingelheim, Bristol-Myers Squibb, Eli Lilly, Galectin Therapeutics, Galmed Pharmaceuticals, Genfit, Gilead, Intercept, Inventiva, Janssen, Madrigal Pharmaceuticals, Merck, NGM Biopharmaceuticals, Pfizer, and Sonic Incytes. He is also co-founder of Liponexus, Inc.

The remaining authors declare that the research was conducted in the absence of any commercial or financial relationships that could be construed as a potential conflict of interest.

Publisher's Note: All claims expressed in this article are solely those of the authors and do not necessarily represent those of their affiliated organizations, or those of the publisher, the editors, and the reviewers. Any product that may be evaluated in this article, or claim that may be made by its manufacturer, is not guaranteed or endorsed by the publisher.

Copyright $\odot 2021$ Fuji, Miller, Nishio, Koyama, Lam, Zhang, Loomba, Brenner and Kisseleva. This is an open-access article distributed under the terms of the Creative Commons Attribution License (CC BY). The use, distribution or reproduction in other forums is permitted, provided the original author(s) and the copyright owner(s) are credited and that the original publication in this journal is cited, in accordance with accepted academic practice. No use, distribution or reproduction is permitted which does not comply with these terms. 